
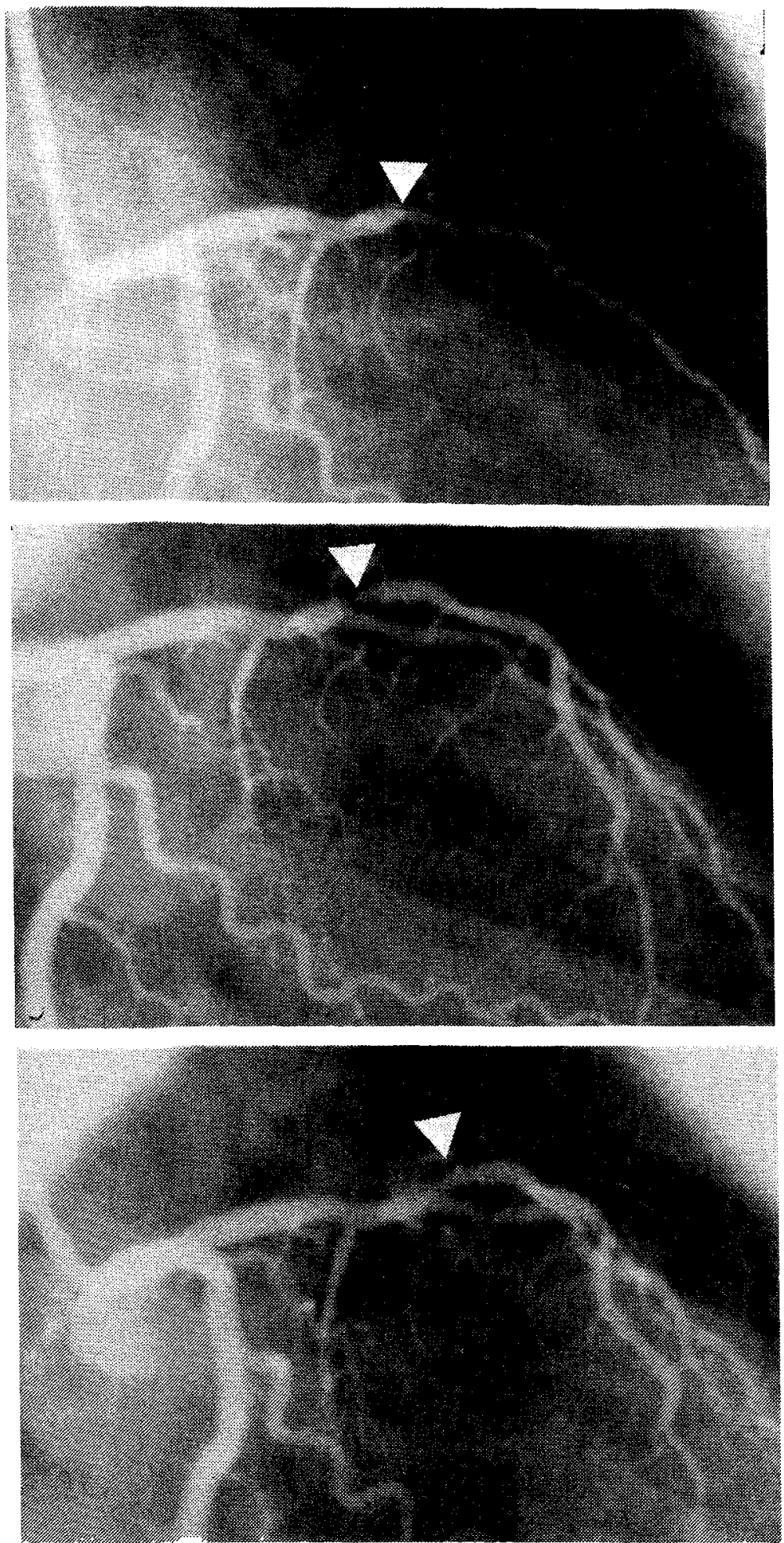

Figure: Anglographic views

Top $=$ complete occlusion of left anterior descending coronary artery (arrow); middle = after ultrasound application; bottom = after additional balloon angioplasty.

introduced into coronary arteries. ${ }^{6}$ We describe a patient with acute myocardial infarction treated with ultrasound.

A 48-year-old woman presented $4 \mathrm{~h}$ after the onset of chest pain with ST elevation in all anterior leads. Because of Wolf-Parkinson-White syndrome and atypical chest pain she was immediately referred to the catheterisation laboratory. Coronary angiography showed a thrombotic occlusion of the proximal left anterior descending artery (figure, top). After informed consent was obtained, the lesion was easily crossed with a $0.36 \mathrm{~mm}$ guide wire. Over the guide wire the ultrasonic probe was advanced through an 8 French guiding catheter to the lesion. The tip of the probe $(1.7 \mathrm{~mm}$ diameter $)$ crossed after $5 \mathrm{~min}$ of ultrasound application. Angiographically the lesion appeared smooth with a residual diameter stenosis of $64 \%$ (figure, middle).

The patient was maintained on high-dose heparin (partial thromboplastin time $>180 \mathrm{~s}$ ) and developed a creatine kinase peak of $1254 \mathrm{U} / \mathrm{L} 6 \mathrm{~h}$ after recanalisation. The next day the patient was restudied by intravascular ultrasound imaging (Hewlett Packard, Boston Scientific), which showed a soft plaque with a minimum lumen diameter of $1.6 \mathrm{~mm}$. Balloon angiplasty at $3.04 \times 10^{5} \mathrm{~Pa}$ with a $2.5 \mathrm{~mm}$ balloon improved the lumen angiographically to a $40 \%$ diameter stenosis (figure, bottom). By ultrasound imaging the minimum diameter was $2.3 \mathrm{~mm}$ without dissection. Further clinical follow-up was uneventful up to discharge after 10 days. A right posterior accessory atrioventricular pathway was successfully treated by radiofrequency ablation 6 days after angioplasty.

This case shows that ultrasound angioplasty may be a potential alternative to balloon angioplasty and thrombolysis in patients with acute thrombotic coronary occlusions. Further experience is needed to establish safety and to define the role of this new technique in fresh thrombotic occlusions.

Christian W Hamm, Jacobus Reimers, Ralf Köster, Wolfram Terres, Georg M Stiel, Dietmar H Koschyk, Karl-Heinz Kuck, Robert J Siegel

Department of Cardiology, University Hospital, Hamburg 20246, Germany; and Cedars-Sinai Medical Center, Los Angeles, California, USA

1 Grines CL, Browne KF, Marco J, et al. A comparison of immediate angioplasty with thrombolytic therapy for acute myocardial infarction. $N$ Engl f Med 1993; 328: 673-79.

2 Zijlstra F, de Boer MJ, Hoorntje JCA, et al. A comparison of immediate coronary angioplasty with intravenous streptokinase in acute myocardial infarction. N Engl F Med 1993; 328: 680-84.

3 Gibbons RJ, Holmes DR, Reeder GS, et al. Immediate angioplasty compared with the administration of a thrombolytic agent followed by conservative treatment for myocardial infarction. $N$ Engl f Med 1993; 328: 685-91.

4 Philippe F, Drobinski G, Bucherer C, et al. Effects of ultrasound energy on thrombi in vitro. Cathet Cardiovasc Diagn 1993; 28: 173-78.

5 Sigel RJ, Gaines P, Crew JR, Cumberland DC. Clinical trial of percutaneous peripheral ultrasound angioplasty. $7 \mathrm{Am}$ Coll Cardiol 1993; 22: 480-88.

6 Siegel R, Gunn J, Tsikaderis D, et al. Therapeutic ultrasonic coronary angioplasty: first 20 cases. Circulation 1993; 88: 1-296.

\section{Bipolar affective psychosis after vigabatrin}

SIR-Vigabatrin is a new and effective inhibitor of gammaaminobutyric acid (GABA) transaminase used in the treatment of therapy-resistant epilepsy. Depression has been reported ${ }^{1}$ in about $4 \%$ of patients on vigabatrin ${ }^{2}$ and also postictal or alternative psychoses ${ }^{3}$ with schizophrenia-like symptoms after effective reduction of seizure frequency. We report a patient with bipolar affective psychosis after vigabatrin.

A 51 -year-old male patient had drug-resistant temporal lobe epilepsy for 26 years due to a benign left-hemispherical temporomesial lesion. Neither he nor his family had a history of affective disorders. Antiepileptic treatment with monotherapy of carbamazepine, phenytoin, or barbiturates in high doses failed to control seizure activity, but combined medication with carbamazepine $(2.8 \mathrm{~g}$ daily) and phenytoin $(0.5 \mathrm{~g}$ daily) achieved a reduction of fits to two temporal lobe attacks per month. However, major sedative side-effects were found to be intolerable and phenytoin was substituted by vigabatrin $(3 \mathrm{~g}$ daily). This treatment was well tolerated, the attacks fell to less than one a month, and there was no longer any sedation. However, 10 weeks after vigabatrin had been added the patient had a hypomanic episode that subsided spontaneously within 4 weeks. 2 months later he developed severe depression and attempted suicide by cutting his wrists. He exhibited delusional thinking with ideas of worthlessness and inappropriate guilt. He also had somatic delusions and was convinced that he had cancer. On admission he was depressed and a few days later he developed a rapid-cycling type of affective psychosis with depressed mood in the morning and a manic state in the afternoon and evening. The manic state was 
characterised by flight of ideas, hyperactivity, socially intrusive behaviour, and lack of concentration. He also showed symptoms of derealisation. An electroencephalogram (EEG) showed a $6-7 \mathrm{~Hz}$ theta rhythm with intermittent frontal bilateral delta waves. No spikes or sharp waves were detected. Before vigabatrin the EEG had shown a slow $8 \mathrm{~Hz}$ alpha rhythm with single bilateral theta-waves without epileptic activity.

After slow withdrawal of vigabatrin and addition of thioridazine $360 \mathrm{mg}$ daily his mood stabilised progressively. Depression subsided within 2 weeks of admission, although he remained hyperactive in the afternoon. Hyperactivity and decreased concentration normalised within the following 8 weeks, corresponding well to psychological test results and improvement of EEG recordings to a slow alpha rhythm, as documented before vigabatrin treatment. Although his mood remained stable, some behavioural alterations persisted including circmstantiality and interpersonal viscosity, as frequently observed in patients with temporal lobe epilepsy. ${ }^{4}$

The bipolar affective psychosis reported here after vigabatrin confirms and extends previous findings related to GABAergic neurotransmission in the development of mood disorders. However, the effect of GABA alone on mood is controversial. ${ }^{2,5,6}$ Our observation suggests that alterations of the GABAergic system not only induce depression, but also may trigger bipolar affective disorders with rapid cycling. Patients with an affective psychosis in their previous history might have a higher risk. ${ }^{1}$ Whether this is also true when there is a pre-existing cerebral lesion as found in our patient is not known. Depressive and manic states must be recognised early in the treatment of epilepsies to avoid serious complications such as suicide. Further studies are needed to identify patients who are susceptible to the psychotomimetic action of the drug, but in view of the seriousness of its side-effects, we recommend that vigabatrin should be confined to patients with otherwise intractable seizures.

\section{Naumann, T Supprian, J Kornhuber, $K W$ Lange, K Reiners} Departments of Neurology and Psychiatry, University of Würberg, 97080 Würburg, Germany

1 Ring HA, Crellin R, Kirker S, Reynolds EH. Vigabatrin and depression. 7 Neurol Neurosurg Psychiatry 1993; 56: 925-28.

2 Mumford JP, Dam M. Meta-analysis of European placebo controlled studies of vigabatrin in drug resistant epilepsy. $\mathrm{Br} \mathcal{F}$ Clin Pharmacol 1989; 27 (suppl 1): 101-07.

3 Sander JW, Hart Y, Trimble $M$, Shorvon SD. Vigabatrin and psychosis. F Neurol Neurosurg Psychiatry 1991; 54: 435-39.

4 Bear D, Freeman R, Greenberg M. Behavioural alterations with temporal lobe epilepsy. In: Blumer D, ed. Psychiatric aspects of epilepsy. American Psychiatric Press, 1984: 197-227.

5 Lloyd K, Zivkovic B, Scatton B, Morselli P, Bartholini G. The GABAergic hypothesis of depression. Prog Neuropsychopharmacol Biol Psychiatry 1989; 13: 341-51.

6 Nurnberger JI, Berrettini WH, Simons-Alling S. Intravenous GABA administration is anxiogenic in man. Psychiatry Res 1986; 19: 113-17.

\section{Serotonin syndrome}

SIR-Neuvonen and colleagues (Dec 4, p 1419) indicate that death may occur due to interactions with moclobemide. The older monoamine oxidase inhibitors (MAOIs) are well known to cause the "cheese" reaction, a hypertensive crisis brought about by interaction with certain foods and drugs, but this is unlikely to occur with moclobemide. ${ }^{1}$ The clinical syndrome that results from interactions between MAOIs and drugs such as clomipramine and citalopram, and also from acute overdose, is less well known. It consists of a serotonin syndrome with a progressive increase in muscle tone leading to widespread muscle spasms, trismus, opisthotonus, and hyperthermia with profuse sweating, tachycardia, hypotension, and widely dilated

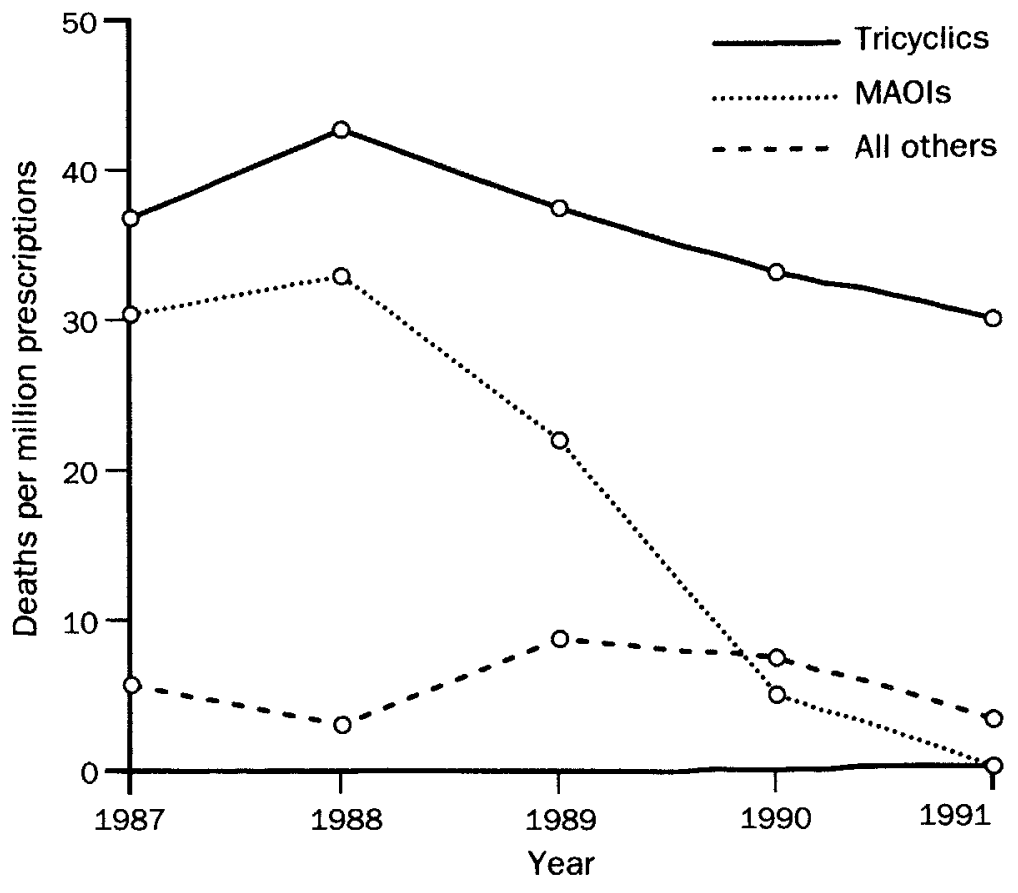

Figure: Yearly fatal toxiclty indices (deaths per million prescriptions, England and Wales) for three major antldepressant drug groups, 1987-91

pupils; ${ }^{2,3}$ death is likely to result from hyperthermia, cardiovascular collapse, or disseminated intravascular coagulation. The London National Poisons Information Service has for several years provided management guidance that MAOI overdose or interaction patients with a core temperature of over $39^{\circ} \mathrm{C}$ should be electively paralysed and mechanically ventilated. ${ }^{4}$ Our experience is that patients who are paralysed before serious complications have developed generally survive. We also believe that this policy has been effective since there has been a steady reduction in the fatal toxicity index of MAOIs each year for the past few years (figure).

\section{John A Henry}

Poisons Unit, Guy's Hospital, London SE1 9RT, UK

1 Freeman H. Moclobemide. Lancet 1993; 342: 1528-32.

2 Blackwell B. Adverse effects of antidepressant drugs. Drugs 1981; 21: 273-82

3 Myrenfors PG, Eriksson T, Sansted CS, Sjoberg G. Moclobemide overdose. F Internal Med 1993; 233: 113-15.

4 Henry JA, Volans GN. ABC of poisoning: psychoactive drugs. $B M \mathcal{F}$ 1984; 289: 1291-94

\section{Pancreas transplantation}

SIR-Remuzzi and colleagues (Jan 1, p 27) claim that a prospective randomised comparison is needed before conclusions can be drawn about the effects of pancreas transplantation. Such trials are difficult because few operations are done in any one centre and multicentre studies are biased by the "centre effect" (immunosuppressive schedules differ greatly between centres). Moreover, the clinical status of uraemic diabetic patients undergoing pancreas transplantation will be so heterogeneous that effective randomisation is unrealistic.

Simultaneous kidney/pancreas transplantation failure rates are, in experienced hands, close to those achieved with kidney or with heart transplantation. 1-year-survival rates (and pancreas rejection rates) are $97 \%(13 \%)$ in Omaha, $90 \%(14 \%)$ in Madison, 93\% (16\%) in Milan, and 95\% (27\%) in Nantes. Moreover, the data reported by Remuzzi refer to 1992 registry results: further improvement was recorded by the international registry in 1993.

Among side-effects of immunosuppressive therapy 